UDC: $75.052: 7.033 .4(467.1)$

DOI: https://doi.org/10.18485/beoiber.2019.3.1.6

\author{
Dora Sesar ${ }^{1}$ \\ Universitat de Zadar \\ Croàcia
}

\title{
ICONOGRAFIA BÍBLICA A LA PINTURA MURAL ROMÀNICA DE LA VALL DE BOÍ: EL CEL DINS DE L'ESGLÉSIA
}

\begin{abstract}
Resum
L'article present tracta de la iconografia bíblica a les pintures murals romàniques conservades de tres esglésies de la Vall de Boí: Sant Climent de Taüll, Santa Maria de Taüll i Sant Joan de Boí, que a principis del segle XX van ser traslladades al Museu Nacional d'Art de Catalunya a Barcelona. S'analitzen les pintures murals d'aquestes tres esglésies, que eren l'única manera de transmetre els missatges i les lliçons bíbliques als fidels illetrats de l'edat mitjana.

Paraules clau: iconografia bíblica, art romànic, pintura mural romànica, Vall de Boí.

\section{BIBLICAL ICONOGRAPHY ON MURAL PAINTINGS IN VALL DE BOÍ: THE SKY IN THE CHURCH}

\section{Summary}

The present article is about biblical iconography on the Romanesque mural paintings conserved from three churches in Vall de Boí: Sant Climent of Taüll, Santa Maria of Taüll, and Sant Joan of Boí, which at the beginning of the $20^{\text {th }}$ century were moved to the National Museum of Catalan Art in Barcelona. This article analyses the mural paintings of these tree churches, as they were the only way to transmit biblical messages and lessons to illiterate medieval believers.
\end{abstract}

Key words: biblical iconography, Romanesque art, Romanesque mural painting, Vall de Boí.

\section{Introducció}

Durant els segles XI i XII a Catalunya es va introduir un nou estil, el romànic, i és també on encara avui dia es troba el conjunt més gran d'art romànic conservat. S'hi troben al voltant de 2500 esglésies romàniques, i això que en van existir moltes més. De

\footnotetext{
1ㅁsesar@gmail.com
} 
totes maneres, un dels territoris més interessants quan parlem d'art romànic català sens dubte és la Vall de Boí, situada al Pirineu català, a la comarca de l'Alta Ribagorça. Realment, és un territori bastant petit, que abasta $219,5 \mathrm{~km}^{2}$, i que per la seva localització sempre ha estat aïllat, especialment a l'edat mitjana. Cada poble de la vall durant el període romànic va obtenir una església i una ermita, fet que sempre ha estranyat als historiadors i historiadors de l'art, ja que no és gaire comú que hi hagin tants conjunts religiosos en un territori tan petit com és aquesta vall. Aquest fet tan estrany es pot explicar amb una mica d'història. Cal imaginar la Catalunya dels segles XI i XII com un territori dividit en nombrosos comtats, i de la mateixa manera la Vall de Boí tenia els seus propietaris, que eren els senyors d'Erill (Fontova i Polo 1999: 14-17). Pel fet d'haver participat en les campanyes de la reconquesta del rei Alfons I, van rebre, com a agraïment, molts diners i altres riqueses. D'aquesta manera, van poder finançar les obres de les esglésies de la vall i esdevenir-ne als principals comitents. Aquest fet, per a ells, significava la garantia de salvació de la seva ànima. (Coma Quintana et al. 2015: 32-37). Les esglésies moltes vegades es construïen a l'entrada del poble, i servien com una mostra del poder dels propietaris. Al contrari, si es construïen a algun lloc aillat, al voltant de les esglésies després es formava el nucli urbà. També és important mencionar que les esglésies romàniques de la Vall de Boí no només servien com a objectes religiosos, sinó que també les seves torres s'utilitzaven per la comunicació i el control d'entrada a la vall (CRVB: 12, $22,25)$.

Un dels aspectes més interessants de la Vall de Boí probablement són les pintures murals de les esglésies de Sant Climent i Santa Maria de Taüll, i de Sant Joan de Boí, que avui dia es conserven al Museu Nacional d'Art de Catalunya a Barcelona. Desafortunadament, no hi ha cap informació sobre qui és l'autor d'aquestes gran obres d'art català, ja que durant l'edat mitjana els artistes es valoraven com qualsevol altre obrer o fuster, fet pel que no hi deixaven escrit el seu nom. Com que és impossible saber el nom exacte dels artistes, els historiadors de l'art diferenciant els estils dels autors de les escenes els van posar els noms: el Mestre de Santa Maria, el Mestre de Taüll i el Mestre de Judici Final. La importància de les pintures murals a l'edat mitjana era molt gran. El poble no sabia llegir, així doncs, l'art es va convertir en l'eina principal per transmetre els missatges bíblics als fidels illetrats (Coma Quintana et al. 2015: 27, 70).

Quan va aparèixer l'estil gòtic, l'art romànic va començar a considerar-se antic i va quedar amagat primer darrere dels nous retaules gòtics, i després, barrocs. Van passar molts anys, o millor dit, molts segles, perquè l'art romànic es descobrís de nou (Coma Quintana et al. 2015: 47). Durant el segle XIX va començar la Renaixença catalana i la recerca d'elements propis de la catalanitat, i va ser en aquesta època quan l'art romànic va ser redescobert (Castiñeiras i Camps 2009: 9). En concret, les pintures murals de les esglésies de Sant Climent, Santa Maria i Sant Joan van ser descobertes l'any 1907 per la missió arqueològica-jurídica a la ratlla d'Aragó, impulsada per l'Institut d'Estudis Catalans. Les pintures redescobertes van despertar l'interès dels noucentistes i també dels col-leccionistes, tant catalans com estrangers (Coma Quintana et al. 2015: 47), que cada 
vegada venien més i més a Catalunya. La pintura mural de l'església de Santa Maria del Mur va ser arrancada i venuda a l'Art Museum de Boston i, per tant, si es volia conservar el patrimoni cultural català a la Vall de Boí, s'havia de prendre una decisió que a molts no va agradar, però que era necessària - arrencar les pintures murals i traslladar-les a Barcelona (Fontova i Polo 1999: 66). Per salvar les pintures la Junta de Museus les va comprar i per fer l'arrencament, una tècnica abans desconeguda a tot Espanya, va contractar a un expert italià, Franco Steffanoni, i els seus ajudants. Les pintures murals arrencades es van traslladar a Barcelona a dalt d'unes mules; aquest procés va durar quatre anys, del 1919 al 1923. Les pintures primerament es van col·locar al Museu d'Art i Arqueologia de la Ciutadella, i després al Palau Nacional de Montjuïc, on avui es troba el Museu Nacional d'Art de Catalunya i el meravellós conjunt d'art romànic català (Castiñeiras 2009: 21-27).

La importància del conjunt romànic de la Vall de Boí la trobem ben demostrada en el fet que la Generalitat de Catalunya el va declarar Bé d'Interès Cultural l'any 1992, i també, la UNESCO el va declarar Patrimoni de la Humanitat l'any 2000 (Coma Quintana et al. 2015: 7). També cal esmentar que alguns dels artistes més grans de la història, com Picasso, Tàpies, Breton o Picabia, van admetre una gran admiració per les pintures de la Vall de Boí (Castiñeiras 2009: 21).

\section{Característiques i simbologia de la pintura mural a la Vall de Boí}

La funció de la pintura mural a la Vall de Boí, com ja s’ha esmentat abans, era didàctica, i funcionava com la biblia pauperum - bíblia pintada per transmetre els missatges bíblics als fidels illetrats. Els ensenyava els elements principals del cristianisme i, a través dels contes bíblics, els donava un exemple de com calia comportar-se durant la seva vida a la Terra, per un dia poder arribar a viure al Regne de Déu. Per tant, era important que els fidels poguessin entendre els missatges pintats, per aquest motiu la pintura havia de ser simple (CRVB: 14). També hem de tenir en compte la perspectiva jeràrquica, o sigui, els personatges més importants es pinten més grans que la resta. Les figures majoritàriament són frontals i estàtiques, sense cap expressió, amb els caps i dits allargats. Destaquen els contorns que formen les siluetes, i els personatges quasi sempre porten vestits decorats d'una manera rica, moltes vegades amb joies, i de colors vívids. També ens hem de fixar que no hi ha perspectiva, els personatges estan representats a un fons format per línies de colors vívids.

En relació amb les influències en la pintura romànica a aquesta vall, es poden destacar tres fonts diferents. La primera que hem de destacar seria la influència bizantina, que en realitat, és la més present, ja que es pot percebre en els vestits rics, plens de joies i ornaments, iguals que els dels gran emperadors bizantins als mosaics de les esglésies de I'Imperi Bizantí. El millor exemple d'aquesta decoració seria la pintura mural de l'absis de 
Santa Maria de Taüll, on veiem el tron ric de la Verge Maria. Els temes també són una mostra d'aquesta influència: el Pantocràtor, la Verge Maria amb els apòstols, els evangelistes (Kluckert 1997: 387-388). El segon art que va contribuir en formació d'aquests frescos és l'italià, i aquesta influència es relaciona amb la Reforma Gregoriana del segle XI, que dicta com ha de ser l'art a les esglésies. L'altre element que va prendre la pintura mural romànica catalana de l'art italià, són els cortinatges en les parts baixes dels murs de l'església, que representen la Terra (Castiñeiras i Camps 2009: 14, 32). Finalment, alguns elements també es relacionen amb la influència del sud de França, amb la regió de Languedoc, i els seus colors vívids, el dibuix energètic i l'aspecte tridimensional que es pot percebre en alguns aspectes de la pintura romànica catalana, com per exemple en els vestits de Sant Climent i Santa Maria de Taüll, l'efecte que l'artista va aconseguir ombrant tons d'un mateix color (Dodds 1993: 194-195).

Ara que ja sabem quines són les característiques de la pintura mural romànica a la Vall de Boí, podem explicar-ne el simbolisme i les maneres de transmetre els missatges bíblics als infidels. En primer lloc, és important destacar que en l'art romànic tot té el seu sentit i el seu significat: cada color, cada línia i cada figura (Quintana, Piñol i Gil 2015: 65). A més, cada escena tenia el seu lloc exacte a l'església, per això, a l'absis sempre s'hi presentava la Divinitat, per la seva forma circular que es considerava perfecte perquè no té ni principi ni fi, és eterna, com Déu. A més, el Crist i la Verge Maria moltes vegades es pintaven dins d'una màndorla, que amb la seva forma ovalada representa el conjunt de dos mons - el cel i la Terra. Als murs laterals hi havia els apòstols i els sants, els intermediaris entre el cel i la Terra. La Terra a les esglésies es representava a les parts baixes dels murs, amb motius vegetals, o amb les cortines (CRVB: 15). A la sortida de l'església, al mur occidental, s'hi pintava el Judici Final, amb sant Miquel pesant les ànimes, amb ell les ànimes salvades, i l'infern, en el que hi havia les ànimes patint en el foc etern. Aquesta escena a la sortida de l'església té un missatge clar: serveix per recordar als fidels que al final de la vida arribarà el Judici Final i que per poder viure al cel, cal comportar-se bé també fora de l'església (Castiñeiras i Camps 2009: 14). Com ja s'ha dit abans, l'art romànic amaga un significat en tot, i en els colors també. Per exemple, el color blanc representa la puresa; el vermell representa la sang i el patiment; l'ocre, la llum i la llibertat; el blau representa el cel; el negre, la maldat; i el verd, l'esperança. La geometria també aporta els seus significats: el cercle és la representació de la perfecció i l'equilibri; el triangle, de la Santa Trinitat; el quadrat, de la Terra; i el pentàgon, del món espiritual i millorat. Així mateix, els nombres també tenen un missatge: 1, unitat i equilibri; 3 , ordre, perfecció, Santa Trinitat; 4, totalitat; 6, pecat; 7, cicles (els set dies de la creació, els set pecats capitals, etc.); 8, resurrecció de Crist; etc. (Coma Quintana et al. 2015: 71-73).

Hem de recordar que les esglésies romàniques a l'edat mitjana estaven totalment pintades, així doncs, totes les escenes mencionades les hem d'imaginar en la foscor d'aquests conjunts arquitectònics monumentals, els quals no deixaven passar la llum del dia. Les figures dels àngels, sants, animals mitològics, la Verge Maria i el Pantocràtor dins d'aquest ambient fosc semblaven reals als fidels que hi entraven amb la llum de les llànties

BEOIBERÍSTICA Vol. III / Número 1 (2019) | 81-99 
d'oli (Fontova i Polo 1999: 22). Es presentaven als espectadors, reals, en moviment, transmetent els seus missatges i les seves lliçons. Els fidels, entrant per la porta, d'alguna manera, entraven al cel: el cel dins de l'església.

\section{Sant Climent de Taüll}

L'església de Sant Climent de Taüll va ser construïda a principis del segle XII i consagrada el dia 10 de desembre de l'any 1123 pel bisbe Ramon Guillem de RodaBarbastre, fet que coneixem per estar escrit a una de les columnes de l'església. Aquesta església és una de les millor conservades i més populars d'aquesta vall, i a dins seu conserva una pintura mural excepcional. L'original es conserva al MNAC, mentre que a l'església avui dia s'hi pot veure la rèplica (Coma Quintana et al. 2015: 84, 87). L'església de Sant Climent probablement va ser totalment pintada, però s'ha conservat només la pintura de l'absis i alguns fragments dels murs i de les columnes. La decoració de l'absis és el que més sorprèn a l'espectador, ja que representa una visió apocalíptica, que amb els seus colors dona a l'ambient un aspecte místic, i d'alguna manera real (Castiñeiras 2009: 71). Les figures representen les escenes de l'Apocalipsi de sant Joan, combinades amb les visions d'Ezequiel, Zacaries i Isaïes, a més amb referències de l'Eclesiastès i Salms (Chordá 2011: 15-19). (foto. 1)

Vaig veure una porta oberta en el cel... vaig veure un tron posat en el cel. Al tron hi seia algú... En el tron, al seu voltant, hi havia quatre vivents plens d'ulls davant $i$ darrere. El primer vivent era semblant a un lleó; el segon vivent era semblant a un toro; el tercer vivent tenia aspecte d'home, i el quart vivent era semblant a una àguila en ple vol... Nit i dia no paraven de repetir: "Sant, sant, sant és el Senyor, Déu de l'univers, el qui era, el qui és i el qui ve." (Ap. 4; 1-8)

Exactament aquest paràgraf de l'Apocalipsi és el que el pintor va representar a l'absis. Les figures estan pintades al davant de les línies grogues i blaves, les grogues representen la Terra, mentre que les blaves representen el cel (Chordá 2011: 21). La porta del cel es va obrir i el cel va baixar a l'església de Sant Climent de Taüll. Aquí hi són tots, el Crist, el Totpoderós al seu tron. Mira fixament a cada fidel que entra a l'església. Amb una mà beneeix als fidels i a l'altra porta un llibre que diu Ego sum lux mundi (Jo soc la llum del món). Les seves mans i els peus surten de la màndorla en la que està assegut, el Crist surt de l'espai celestial i entra a l'església amb els fidels. Porta una túnica blanca amb els punts vermells ("Portava el mantell xop de sang", Ap. 19; 13). Descansa els seus peus sobre un escambell de color gris, que representa el caos i la mort ("Seu a la meva dreta, mentre faig dels enemics l'escambell dels teus peus", Salm 110; 1). A més, el Crist és l'únic que du sandàlies, mentre que la resta van descalços. D'aquesta manera, ell demostra la seva superioritat, ja que la resta s'ha de descalçar en un lloc sagrat. Déu li va dir a Moisés 
al Sinaí: "No t'acostis. Treu-te les sandàlies, que el lloc que trepitges és sagrat”. (Ex. 3; 5) Als costats del Pantocràtor hi ha dues lletres, penjades de tres fils ("El fil triple no es trenca de presa" Eclesiastès: 4,12) (Chordá 2011: 15-18). Són l'alfa i l'omega, les lletres de l'alfabet grec que representen el principi i el fi: el Crist és el principi i el fi de tot. Amb ell han vingut els quatre evangelistes amb els seus símbols: sant Marc amb un lleó, sant Lluc amb un brau, sant Mateu representat com un home, i per últim, sant Joan amb una àguila a les mans (Coma Quintana et al. 2015: 88). Amb el Crist i els evangelistes també hi ha dos serafins, que segons la visió d'Isaïes també glorificaven al Totpoderós i cridaven "Sant, sant, sant és el Senyor de l'univers, tota la terra és plena de la seva glòrian (Is., 6; 2-3) Els serafins estan plens d'ulls, que representen el poder i l'omnipresència del Crist (Chordá, 2011: 18). En relació amb aquest apartat superior de l'absis, també cal esmentar les quatre rodes a les que hi ha els evangelistes Marc i Lluc, que al-ludeixen a la visió d'Ezequiel (Castiñeiras 2009: 70): "Totes les rodes eren iguals. [...] Quan avançaven, ho podien fer en totes quatre direccions, però sense girar-ses. (Ez., 10; 10-11).

A diferència d'aquesta part superior de l'absis, que representa el cel i és dramàtica, sembla que les figures s'estiguin movent, a baix hi ha la Terra, representada com un espai tranquil, amb els personatges estàtics (Chordá 2011: 21). A sota dels arcs que representen l'arquitectura imaginària de Jerusalem hi ha els apòstols Tomàs, Bartomeu, Joan, Jaume, Felip, i amb ells, la Mare de Déu. Ella a la mà porta una patena amb la que recull la sang del Crist, el sacrifici de l'Eucaristia (Castiñeiras 2009: 72). L'arquitectura imaginària està formada per unes columnes amb els capitells en forma d'unes flors tancades, i connectades pels arcs. Només uns capitells són diferents de la resta -els capitells de les columnes entre les que es troba sant Joan, l'autor de l'Apocalipsi i de tota l'escena representada aquí, per això, calia destacar-lo d'alguna manera. Aquests capitells tenen forma d'unes flors obertes, i a més a més, sant Joan també destaca per tenir el llibre representat a aquest absis a les mans, alineat amb el llibre del Pantocràtor, que també en porta un, obert en la pàgina que porta el seu missatge: Ego sum lux mundi (Chordá 2011: 19). 


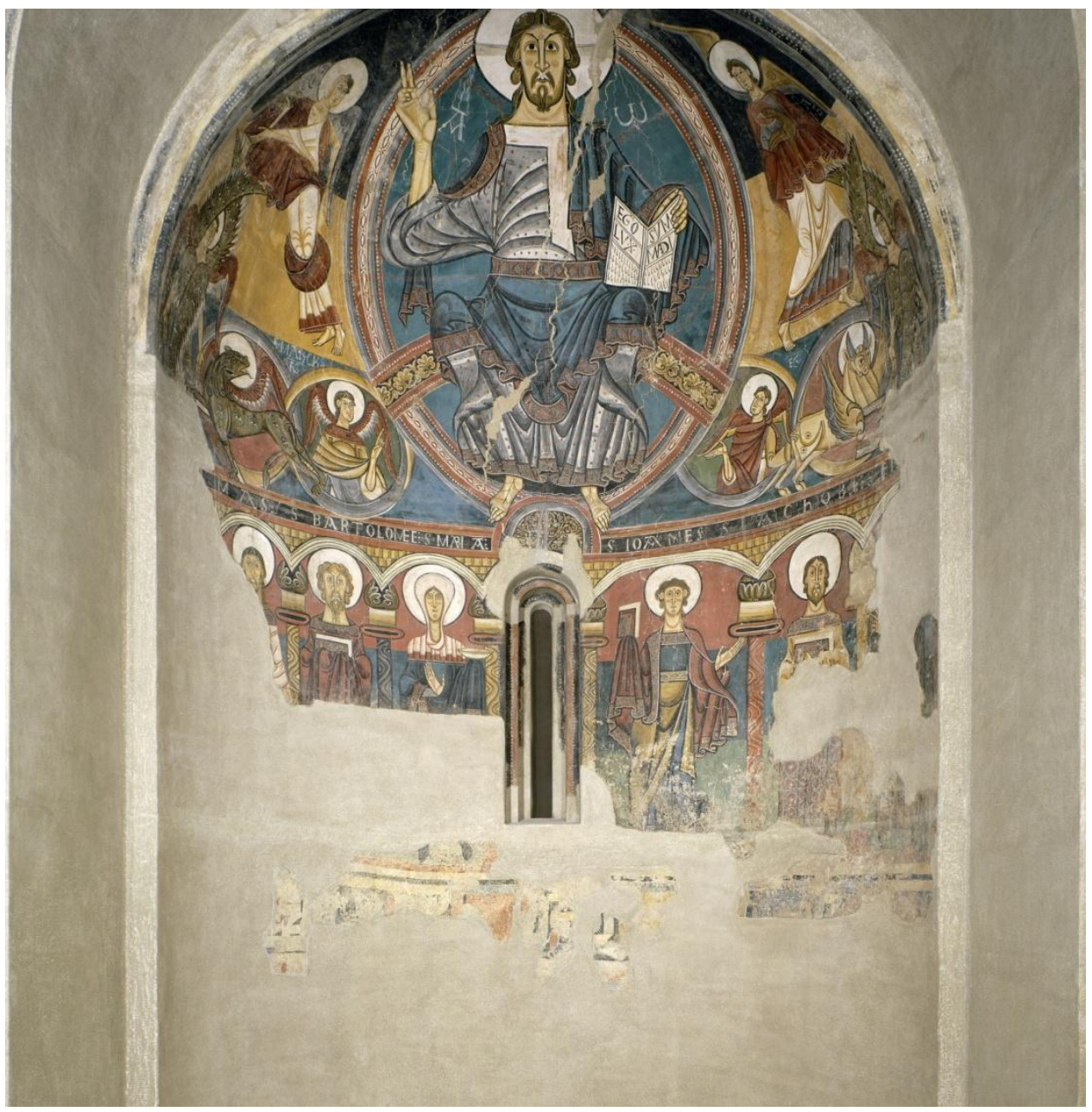

1. Absis de Sant Climent de Taüll

(๔ Museo Nacional d'Art de Catalunya, Barcelona, 2019, n.inv.015966-000)

També hi ha restes de pintura a dos arcs triomfals de l'absis principal. A la clau del primer arc hi ha un cercle (representa la perfecció) amb l'anyell apocalíptic amb "set ulls del Senyor que inspeccionen el paísn (Zac.,4; 10) (Chordá 2011: 18) (foto. 2). A la clau de l'altre arc hi ha la Dextera Domini, la mà de Déu omnipresent (foto. 3). Als arcs triomfals també hi trobem a Caín i Abel, i la paràbola del pobre Llàtzer i el ric epuló (Coma Quintana et al., 2015: 89). La història diu que el pobre Llàtzer ple de llagues cada dia s'asseia a la porta del ric epuló per poder-se menjar les restes dels seus dinars, però ell no li feia cas. Quan els dos van morir, Llàtzer va arribar al cel i s'asseia a taula al costat d'Abraham, mentre que el ric epuló va acabar patint a l'infern. Quan el ric epuló ho va intentar arreglar, ja era tard i Abraham li va dir: "Fill, recorda't que en vida et van tocar bens de tota mena, mentre que Llàtzer només va rebre mals. Ara, doncs, ell troba aquí consol i tu, en canvi, sofriments" (Lluc, 16; 25). Aquesta escena, com totes, té un fort 
significat i missatge pels fidels: els que pateixen durant la vida, al final rebran consol al Regne de Déu. (foto. 4)

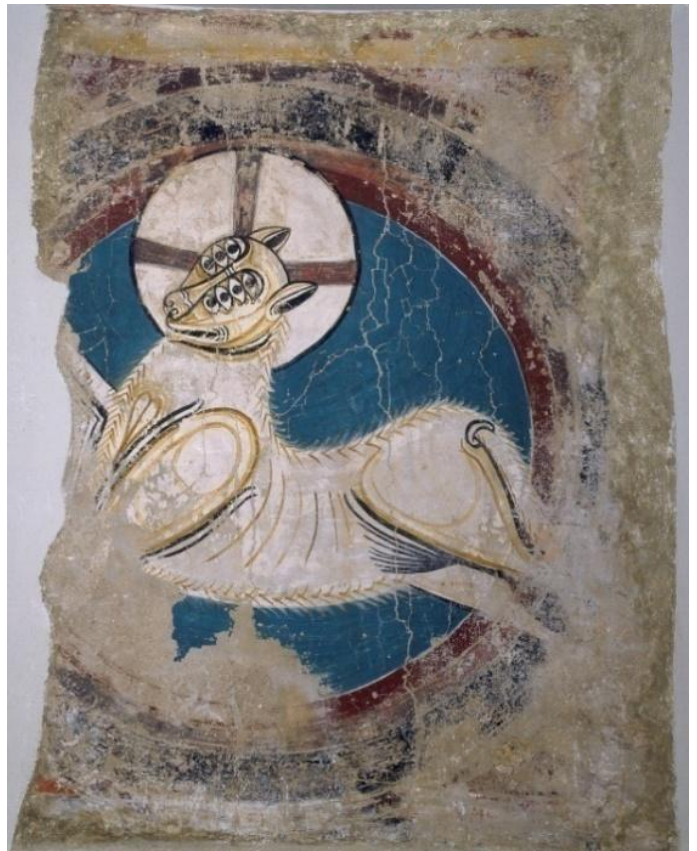

2. Anyell apocalíptic de Sant Climent de Taüll

(๔) Museu Nacional d'Art de Catalunya, Barcelona, 2019, n.inv. 015806-000)

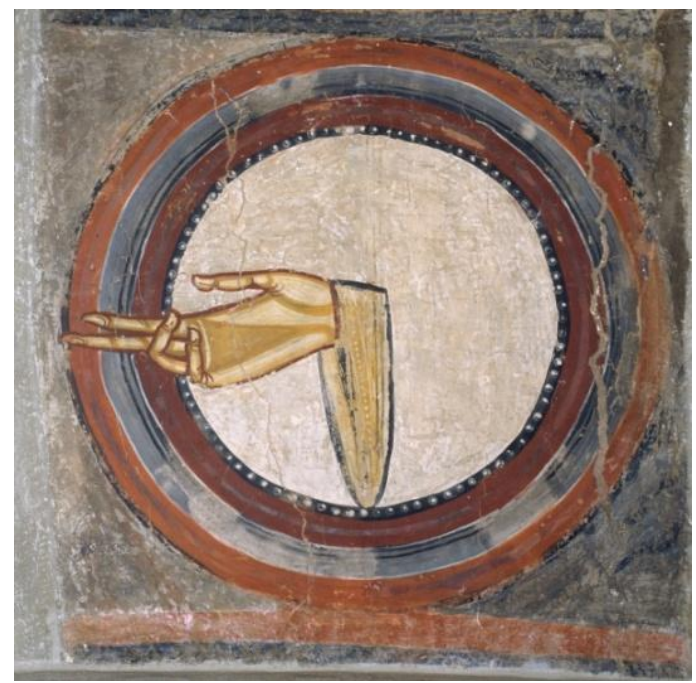

3. Mà de Deu de Sant Climent de Taüll

(๔ Museu Nacional d’Art de Catalunya, Barcelona, 2019, n.inv. 015968-000) 


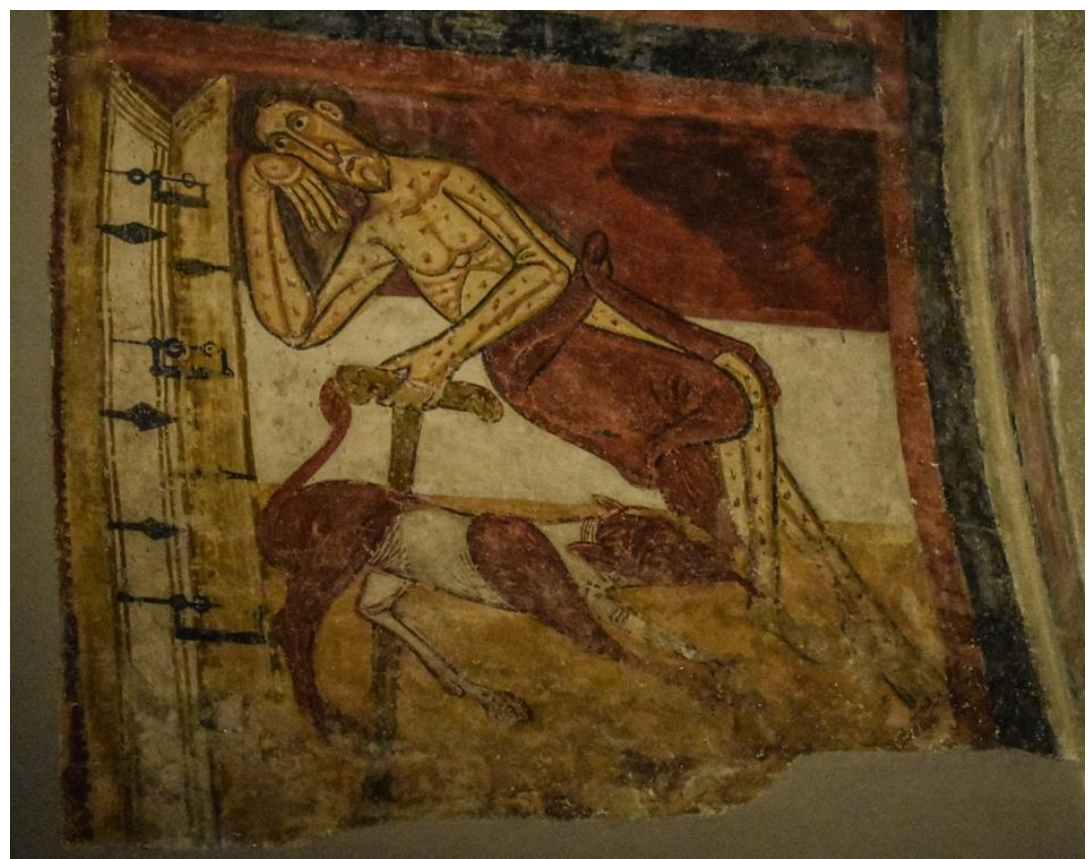

4. Llàtzer amb un gos llepant-li les llagues, MNAC

\section{Santa Maria de Taüll}

Després que Jesús va néixer a Betlem de Judea, en temps del rei Herodes, vingueren uns savis d'Orient, i en arribar a Jerusalem, preguntaven: On és el rei dels jeus que ha nascut? Hem vist sortir a l'Orient la seva estrella i venim a adorar-lo. (Mat. 2; 1-2)

Aquesta escena, l'Epifania (la visita dels tres savis) és l'escena principal de l'absis de l'església de Santa Maria, que es troba al centre del petit poble de Taüll, i que va ser consagrada el dia 11 de desembre de 1123 pel Ramon Guillem, el mateix bisbe que només un dia abans havia consagrat l'església de Sant Climent (foto. 5). A l'absis central hi ha representada la Verge Maria amb el Nen Jesús en un tron decorat d'una manera molt rica, que demostra una forta influència bizantina. A la seva falda, el Nen Jesús està beneint als espectadors amb la mà dreta (Coma Quintana et al. 2015: 93-98). A dalt de la Sagrada Família, al cel s'hi veuen dues estrelles, que representen l'estrella que va informar als savis que el rei dels jueus havia nascut (Fontova i Polo 1999: 158). El moment representat a l'absis central de Santa Maria és quan els savis ja han arribat a adorar el rei portant-li els seus regals. A nostra esquerra veiem a Melcior i, a la dreta, Gaspar i Baltasar. Els podem identificar fàcilment ja que els seus noms estan escrits sota cada figura. Una sanefa de motius geomètrics separa l'escena principal del registre de sota, en el que es troben sis apòstols, sota els arcs, semblants als de l'absis de Sant Climent. A sota d'aquest registre hi trobem el bestiari, o sigui, els animals fantàstics, a dins dels cercles, i més avall 
hi trobem els cortinatges, que representen la terra. (Coma Quintana et al., 2015: 93-98). Aquest absis també té el doble arc triomfal, al centre hi ha l'Agnus Dei (foto. 6), i a la dreta la Dextera Domini, la presència de Déu, a la que Abel regala un anyell (Fontanova i Polo, 1999: 159) (foto. 7). Les pintures murals de l'absis es consideren l'obra amb més qualitat d'aquesta església, mentre que la resta de l'església va ser pintada per altres mestres, i les seves obres són de menys qualitat (Castiñeiras, 2009: 72).

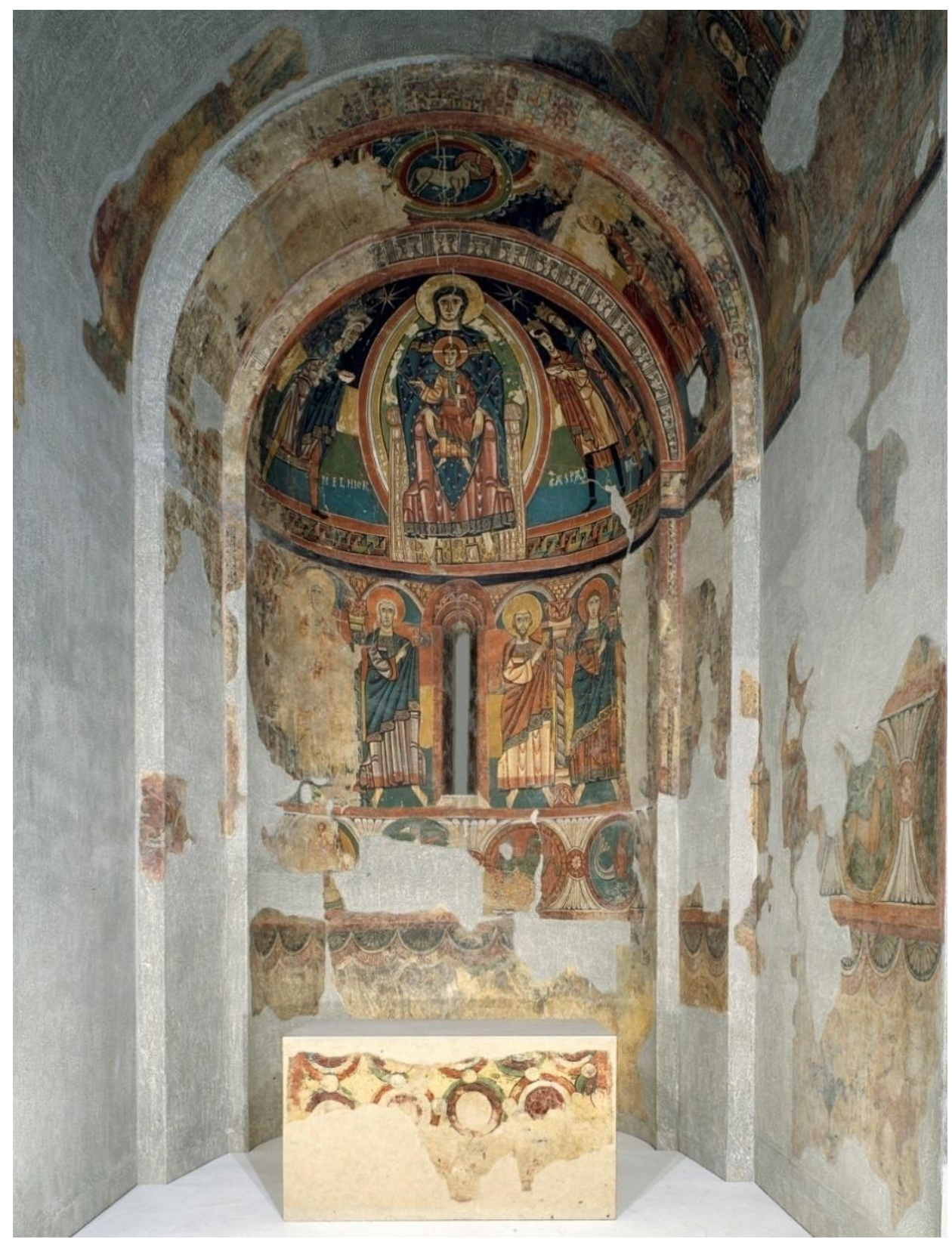

5. Absis de Santa Maria de Taüll

(๔) Museu Nacional d'Art de Catalunya, Barcelona, 2019, n.inv. 015863-000) 


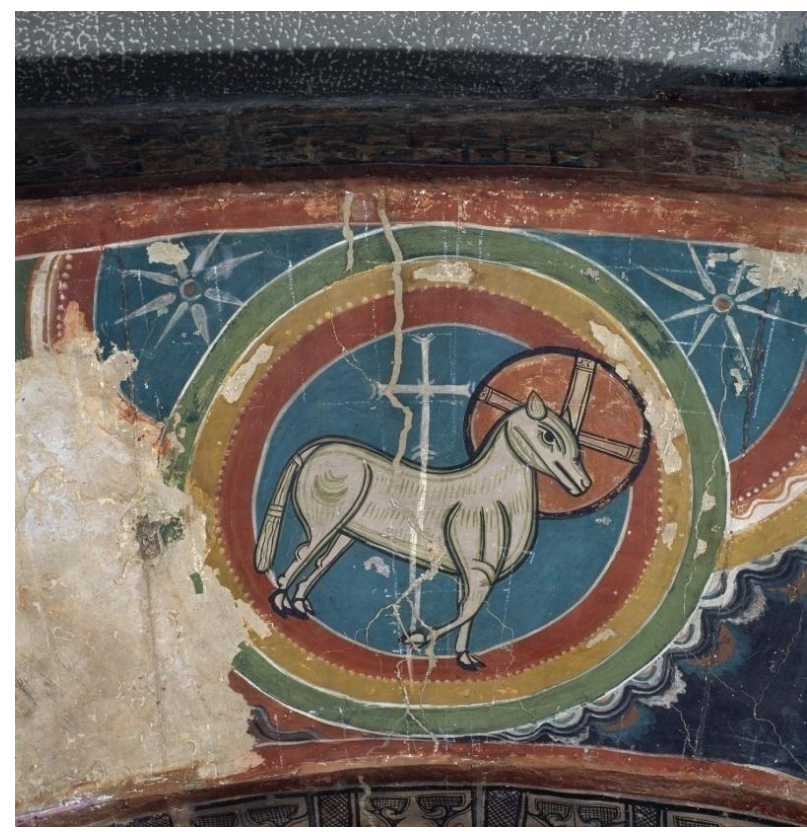

6. Anyell apocalíptic de Santa Maria de Taüll

(๔ Museu Nacional d'Art de Catalunya, Barcelona, 2019, n.inv. 015861-000)

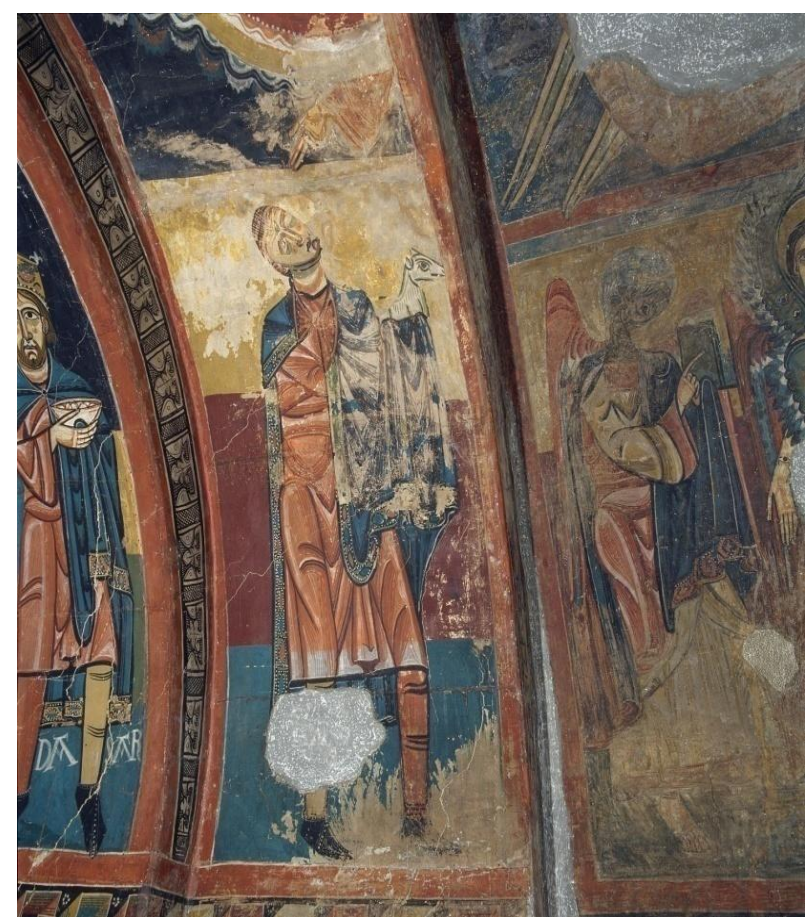

7. Arc de l'Ofrena d'Abel de Santa Maria de Taüll

(๔ Museu Nacional d'Art de Catalunya, 2019, n.inv. 015861-000) 
Les naus laterals estan decorades amb les escenes separades en tres registres: al registre superior trobem escenes de la vida dels sants, al central hi veiem les escenes de la vida de Crist, i a l'inferior, els cortinatges (Fontova i Polo 1999: 159) (foto. 8).

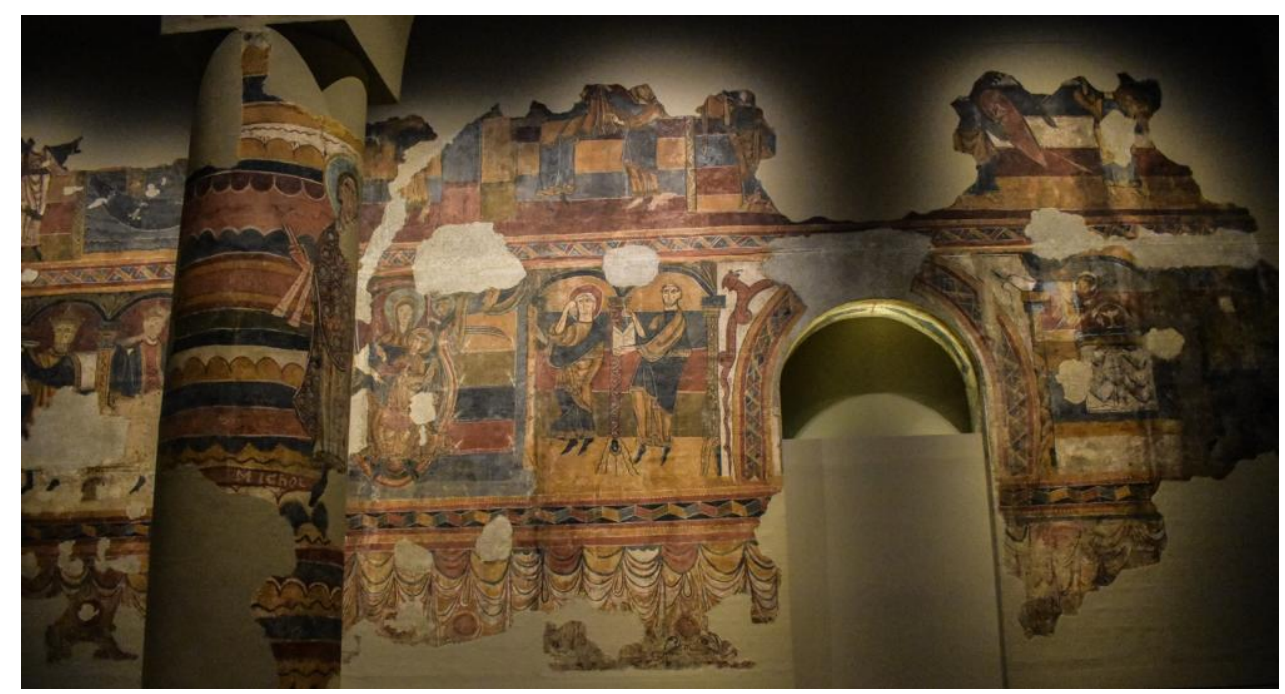

8. La nau lateral de Santa Maria de Taüll, MNAC

A la nau lateral, apropant-se al mur occidental i sortida de l'església, s'hi troba l'infern, que recorda als fidels que el foc etern els pot esperar després del Judici Final, si no viuen d'acord amb els manaments de Déu (foto. 9).

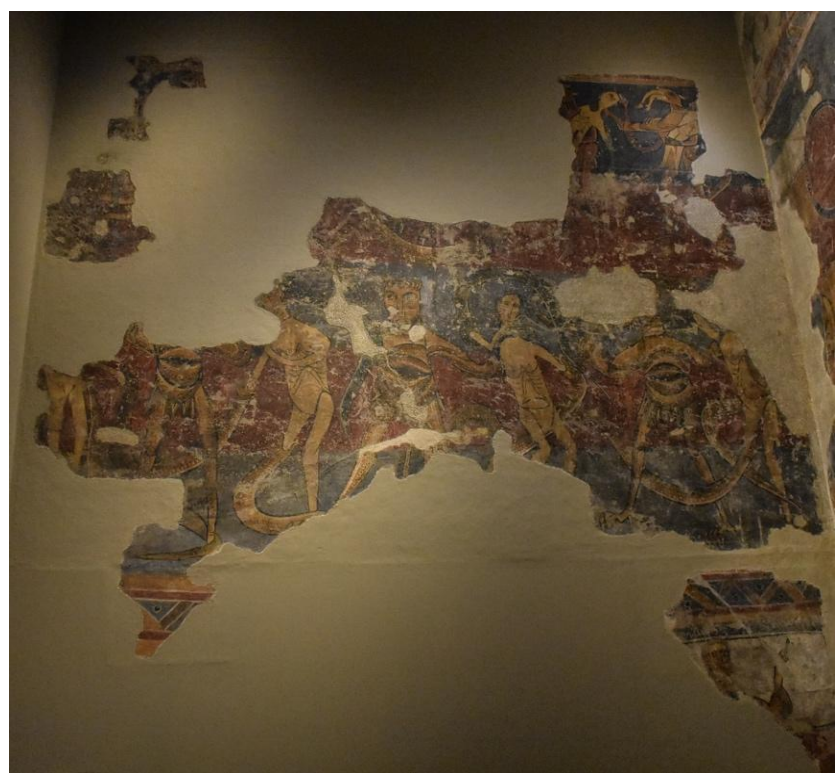

9. L'infern de Santa Maria de Taüll, MNAC 
A la sortida de l'església, al mur occidental, tenim l'escena del Judici Final, que portava els missatges ben clars: calia que els fidels en sortir de l'església seguissin vivint amb la fe (foto. 10). Al centre s'hi trobava la figura majestuosa de Crist, que ha baixat del cel per jutjar els fets de la vida de cadascú, però ja no es conserva. L'acompanyen nombrosos àngels, però en destaca un que porta la creu de victòria sobre la mort. A l'esquerra del registre de sota veiem a sant Miquel amb la balança que està pesant les ànimes: és el que pesant els pecats i les virtuts decidirà sobre el futur de cada persona. A la dreta tenim l'infern i les ànimes nues que estan destinades a patir per sempre en el foc etern (Castiñeiras 2009: 72). En veure les figures poderoses del Crist, sant Miquel i els àngels, i les ànimes a l'infern, els fidels s'emportaven un recordatori al món exterior —cal comportar-se bé durant la vida i seguir l'exemple dels sants i bisbes, els quals trobem representats en les columnes de l'església, per guanyar-se la vida eterna en el Regne de Déu.

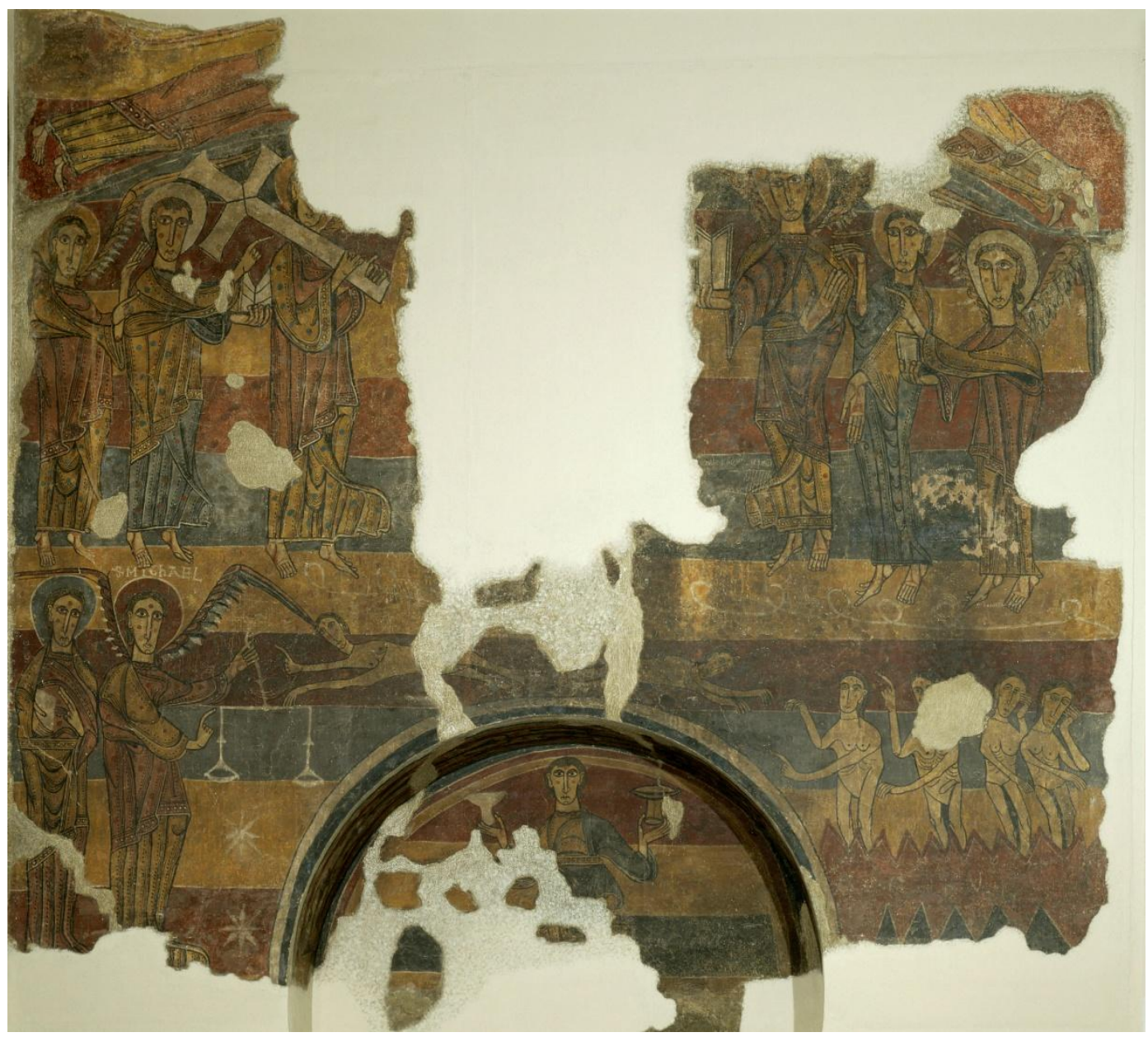

10. Judici Final de Santa Maria de Taüll

(๔ Museu Nacional d’Art de Catalunya, Barcelona, 2019, n.inv. 015836-000) 
Al mur occidental els fidels també es trobaven amb les figures de David i Goliat en Iluita (Fontova i Polo, 199: 159) (foto. 11), la lluita que guanya el més petit i menys fort, amb l'ajuda de Déu. David li va dir a Goliat: "Tu vens contra mi amb l'espasa, la llança $i$ la javelina, però jo vinc contra tu en nom del Senyor de l'univers, el Déu de les tropes d'Israel." (Sam., 17; 45) El significat d'aquesta escena a la sortida de l'església és que els fidels sempre han de recordar que el bé sempre guanyarà el mal, que cal confiar i lluitar en nom de Déu, que sempre estarà al seu costat.

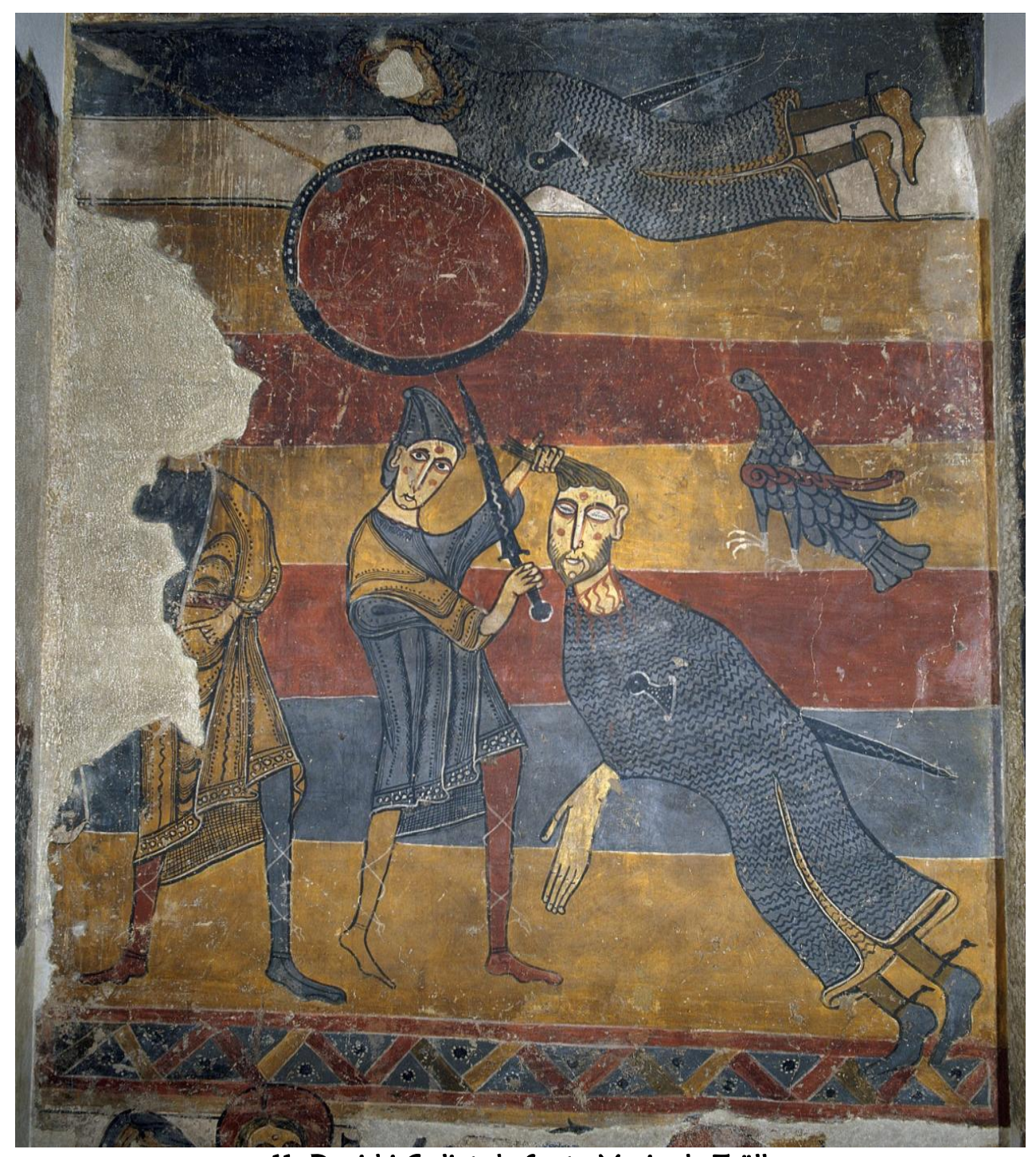

11. David i Goliat de Santa Maria de Taüll

(๔) Museu Nacional d'Art de Catalunya, Barcelona, 2019, n.inv. 015965-001) 


\section{Sant Joan de Boí}

El poble de Boí durant l'edat mitjana era un dels pobles més importants de la vall. Estava fortificat, $i$ avui dia és possible veure les restes de les muralles. L'església de Sant Joan de Boí és un cas especial dins del conjunt romànic de la Vall de Boí. Ja sabem que les esglésies tenien la pintura mural interior i exterior, però aquesta església és la única de la vall on es conserven restes de la decoració exterior. Trobem l'escena de la Teofania a la façana nord, a dalt de l'arc de la porta. Al centre es troba un cercle agafat per dos àngels, i a dins probablement hi havia un crismó. Al voltant del cercle veiem els tres reis mags, que venen a portar els regals al Nen Jesús (Coma Quintana et al. 2015: 104-105) (foto. 12).

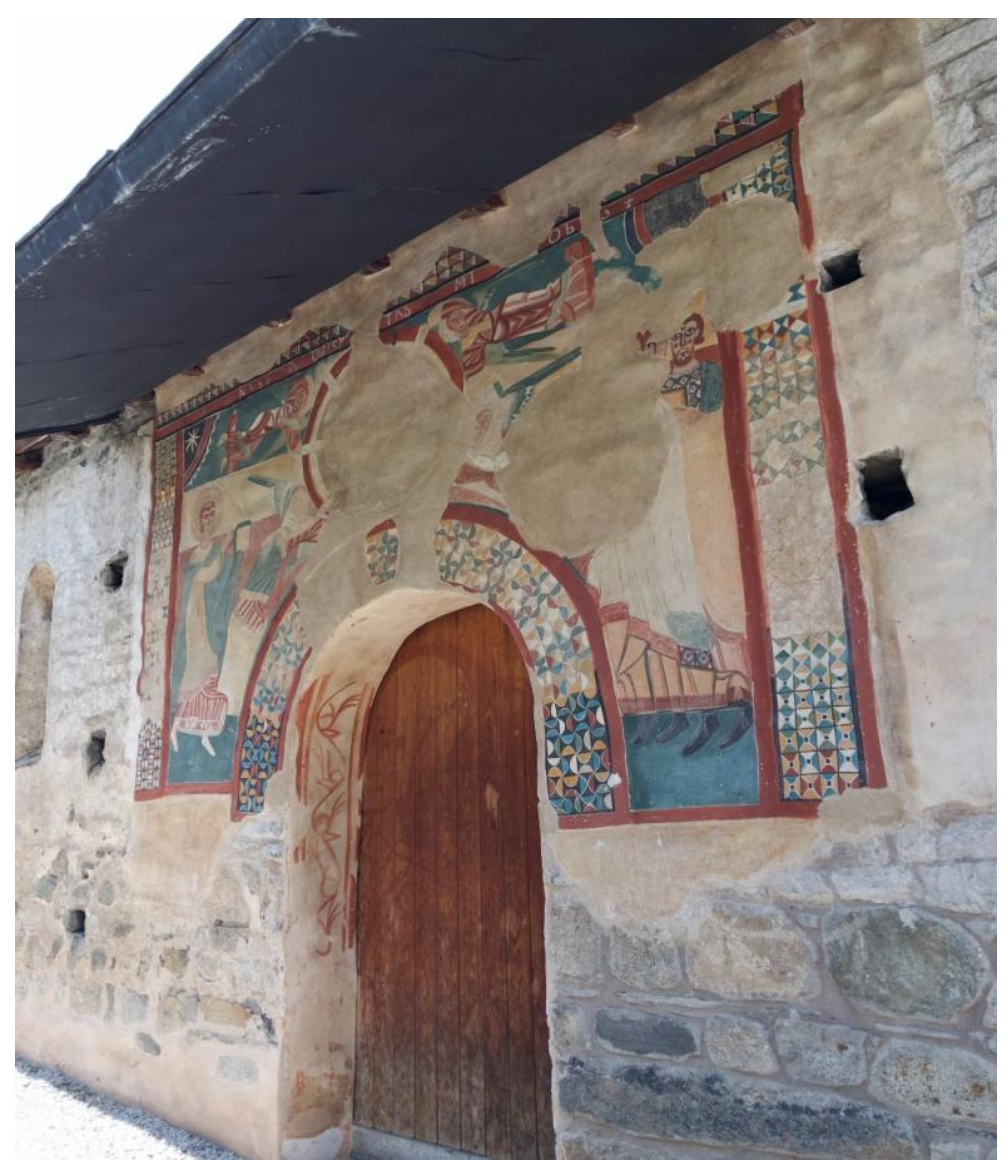

12. La pintura mural exterior a Sant Joan de Boí (rèplica, original al MNAC)

A més a més, també es conserva un conjunt magnífic de pintura mural romànica a dins de l'església: a la nau lateral nord, a la nau sud, als intradossos dels arcs que separen les naus i al mur occidental (Guardia i Mancho 2008: 145). Segons les escenes que s'han 
conservat, sembla que els frescos dels murs laterals estaven dividits en dos nivells: a dalt hi havia sants i benaurats que representen el cel i, baix d'ells, el bestiari, els animals fantàstics, que a més, també es trobaven als intradossos dels arcs que separen les naus, i que representen la Terra. El cicle de pintura mural es tancava al mur occidental, o sigui a la sortida de l'església, on com sempre, tenim l'escena del Judici Final, que recordava als fidels què és el que els espera després d'aquesta vida (Coma Quintana et al. 2015: 106). Una de les escenes més interessants de tot el conjunt és l'escena de la lapidació de sant Esteve, que es troba al mur que separa la nau central de la nau lateral sud, entre les escenes dels sants (Fontova i Polo 1999: 124) (foto. 13). Sant Esteve feia grans prodigis entre el poble, cosa que feia que li tinguessin enveja, així que uns homes van decidir dir mentides sobre ell, afirmant que sant Esteve pronunciava paraules blasfemes contra Moisès i contra Déu (Fets dels Apòstols, 6; 11), i el van portar a lapidar. Aquí veiem aquesta escena: tres personatges li estan llençant pedres al sant, mentre ell es troba a la dreta, agenollat i pregant-li a Déu, que està present a través de la Dextera Domini, la mà de Déu que surt del cel. Mentre el lapidaven, sant Esteve va cridar amb tota la força: "Senyor, no els tinguis en compte aquest pecat" (Fets dels apòstols, 7; 60), i en dir això, va morir. Aquesta escena representa una lliçó molt important pels fidels: cal perdonar als enemics, no desitjar-los mal ni venjar-se. Déu sempre està amb els fidels, ho veu tot, i els que pateixen i els que perdonen al seu enemic viuran eternament en el Regne de Déu.

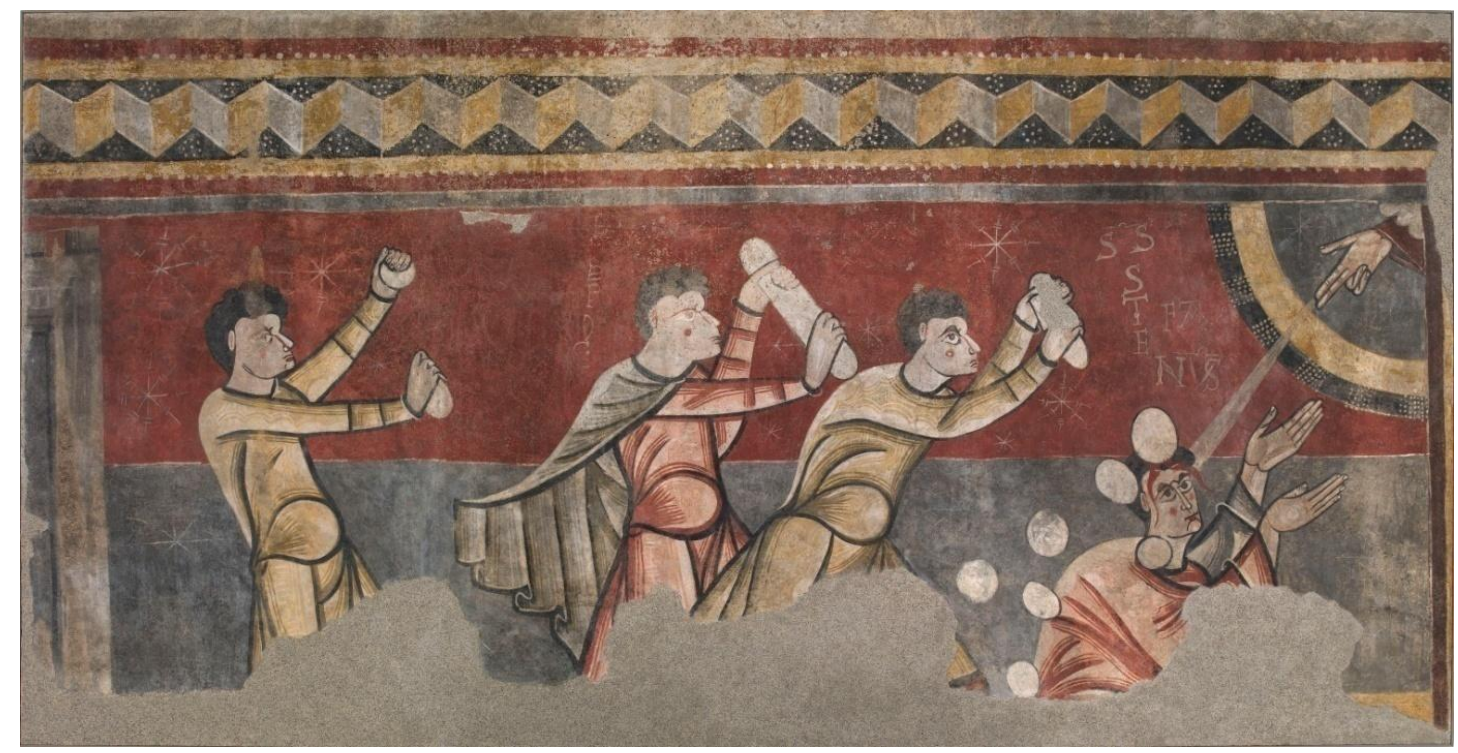

13. La lapidació de sant Esteve

(๔ Museu Nacional d’Art de Catalunya, Barcelona, 2019, n.inv. 015953-000)

A la part central del mur nord hi trobem l'escena dels joglars (MNAC) (foto. 14). Hi veiem un músic, un malabarista i un equilibrista (Coma Quintana et al. 2015: 109). De fet, aquesta escena no té cap relació amb la Bíblia, però pot ser que estigui vinculada amb la celebració de la consagració de l'església (MNAC). També es podria relacionar amb 
l'alegria i la festa al cel de les ànimes salvades, que s'han merescut la vida en el Regne de Déu. Els fidels a l'edat mitjana en aquesta escena, potser trobaven la força, potser els ensenyava que, després de tots els patiments terrenals, arribaria el dia en què començaria la vida eterna, plena de consols i alegria, al costat de Déu, els sants i benaurats.

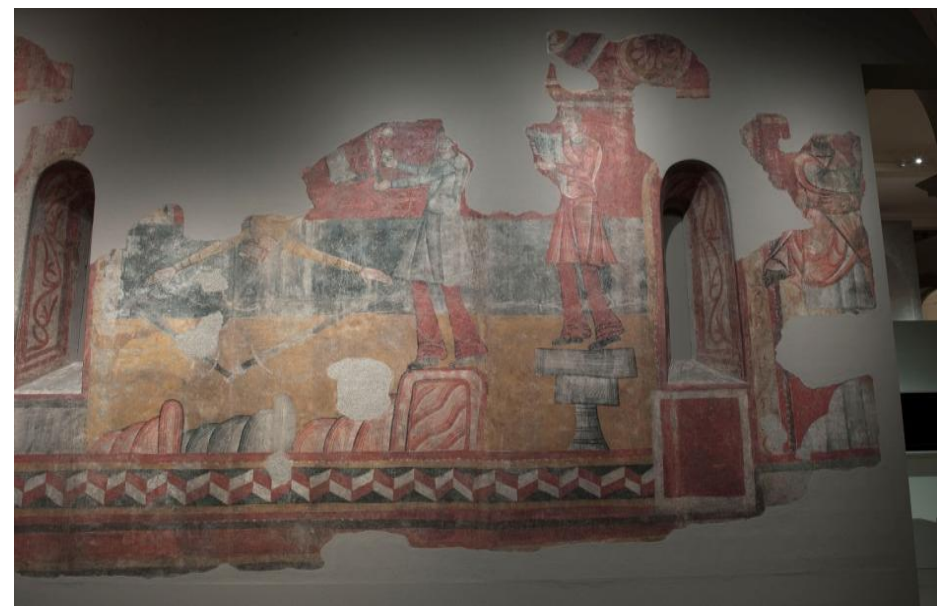

14. Els joglars de Boí

(๔ Museu Nacional d’Art de Catalunya, Barcelona, 2019, n.inv. 015955-000)

Per concloure, també caldria esmentar el gall, que es troba al timpà de la porta nord. El gall que canta avisa d'un nou dia, i per tant, és un símbol de la resurrecció (Coma Quintana et al. 2015: 108): aquesta vida només és una part del viatge, una part plena de sacrificis i patiments, però si es viu d'acord amb les regles, servirà com a entrada al regne celestial etern, ple de consol i alegria (foto. 15).

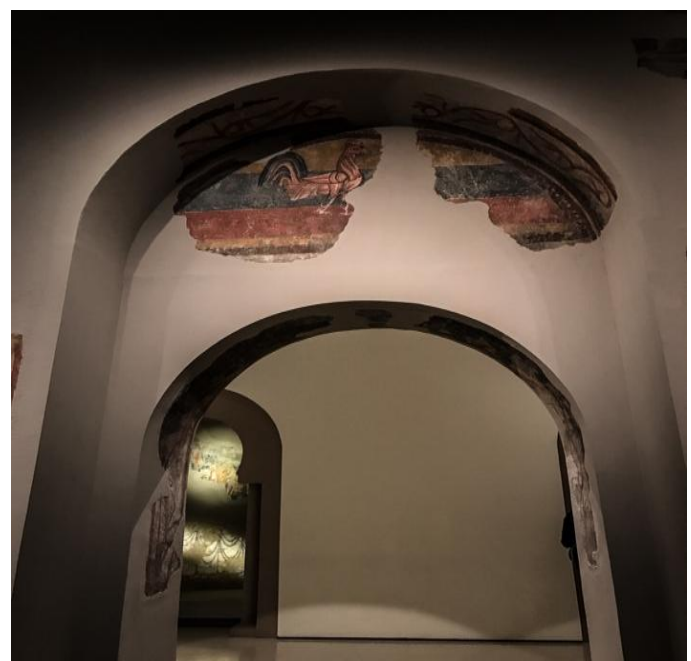

15. El gall al timpà de la porta nord de Sant Joan de Boí, MNAC 


\section{Conclusió}

La Vall de Boí és un dels fenòmens que més sorprèn als historiadors de l'art medieval. En un territori tan petit s'hi va construir un gran nombre d'esglésies romàniques que, a més, avui dia representen el millor conjunt conservat d'arquitectura romànica. A més de l'arquitectura, s'han conservat les pintures murals monumentals, però cal recordar una vegada més que a les esglésies de la vall s'hi troben les rèpliques, mentre que els originals es van transportar al Museu Nacional d'Art de Catalunya a Barcelona. S'han conservat tres conjunts magnífics de pintura mural a les tres esglésies de Sant Climent, Santa Maria i Sant Joan. Cada una d'aquestes esglésies té un programa iconogràfic molt ric, que segurament va ser creat pels bisbes, ja que eren els únics que coneixien bé la iconografia bíblica. El poble, al contrari, no sabia llegir, així que l'art, especialment la pintura, es va convertir en el mètode principal per explicar les històries bíbliques, transmetre els missatges principals, ensenyar els bons exemples dels sants, donar consol $\mathrm{i}$ esperança d'una vida eterna al cel. Per poder transmetre aquests missatges, l'art havia de ser simple i clar. La seva funció principal no era estètica, sinó didàctica. Els fidels entraven a les petites esglésies romàniques fosques, i hi podien veure el cel, el que els esperava després del Judici Final. Les figures de Déu, de la Verge Maria i dels sants baixaven del cel a l'absis de les esglésies, semblaven tan reals mirant als fidels, beneint-los, portant-los missatges. Els sants que es troben a les parets $\mathrm{i}$ a les columnes de les esglésies representen un bon exemple a seguir, ells s'han guanyat la vida eterna durant la seva estada a la Terra, i és el que haurien de fer els fidels també. Les escenes com la lluita de David i Goliat de Santa Maria de Taüll, o la lapidació de sant Esteve de Sant Joan de Boí, són exemples bíblics que servien com a consol, transmetien el missatge que al final, sigui com sigui, sempre guanyarà el bé. En sortir de l'església, els fidels sempre es trobaven amb l'escena que més por feia: el Judici Final. Sant Miquel pesant les ànimes: és el que s'esperaven ells també després de la mort. Les escenes horroroses de l'infern i d'ànimes patint en el foc, eren un recordatori que en sortir de l'església cal portar les lliçons apreses dels murs de l'església. Els fidels entrant a la foscor de la petita església romànica, d'alguna manera, entraven al cel: el cel dins de l'església.

\section{BIBLIOGRAFIA}

Castiñeiras, Manuel. "La pintura mural". El romànic a les col/lecions del MNAC, Barcelona: Museu Nacional d'Art de Catalunya; Lunwerg Editores, 2009: 21-50. Imprès.

Castiñeiras, Manuel, i Jordi Camps. "Introducció al romànic a Catalunya”. El romànic a les col-lecions del MNAC, Barcelona: Museu Nacional d'Art de Catalunya; Lunwerg Editores, 2009: 9-21. Imprès. 
CRVB: Centre del Romànic de la Vall de Boí. La Vall de Boí: Mil anys d'art romànic. Web. 10 Nov. 2018.

Chordá, Federic. "Dios renovador en el ábside de Sant Climent de Taüll”. Butlletí de la Reial Acadèmia Catalana de Belles Arts de Sant Jordi, 25 (2011): 15-38. Web. 18 Nov. 2018.

Coma Quintana, Laia, et al. La Vall de Boí: Mil anys d'art romànic. Calafell: Gràfiques Raventós Suau, 2009. Imprès.

Dodds, Jerrillynn D. The art of medieval Spain, A.D., 500-1200. New York: Metropolitan Museum of Art, 1993. MetPubliacations. Web. 21 Nov. 2018.

Fontova, Rosario, i M. Carme Polo. Romànic de la Vall de Boí. Barcelona: Dissenys culturals, 1999. Imprès.

Guardia, Milagros, i Carles Mancho. "Pedret, Boí o dels orígens de la pintura mural románica catalana». Les fonts de la pintura romànica, Barcelona: Publicacions i edicions de la Universitat de Barcelona, 2008: 117-159. Web. 1 Des. 2018.

Kluckert, Ehrenfried "Romanesque painting". Toman Rolf (ed.), Romanesque: architecture, sculpture, painting, Cologne: Könemann, 1997: 382-462. Print.

MNAC: Museu Nacional d'Art de Catalunya. Sants i joglars de Boí. Web. 8 Des. 2018. 